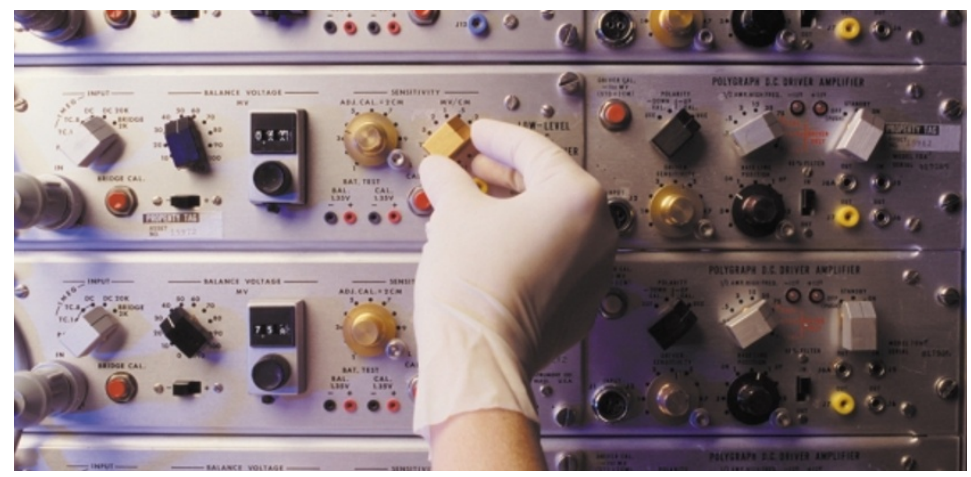

NEUROTRANSMITTERS

\section{Switching channels}

Although GABA ( $\gamma$-aminobutyric acid) is best known as the main inhibitory neurotransmitter in the adult brain, it can actually excite neurons during embryonic brain development, and in structures such as the hippocampus, neocortex and hypothalamus, its inhibitory properties only emerge after birth. The $\mathrm{GABA}_{\mathrm{A}}$ receptor is a chloride channel, and the balance between its excitatory and inhibitory properties depends largely on the $\mathrm{Cl}^{-}$gradient across the cell membrane. During postnatal development, the switch of GABA-mediated synaptic transmission from excitation to inhibition coincides with the upregulation of expression of the $\mathrm{K}^{+}-\mathrm{Cl}^{-}$co-transporter $\mathrm{KCC} 2$. One consequence of this upregulation is that more $\mathrm{Cl}^{-}$ions are pumped out of the cell, lowering the resting intracellular $\mathrm{Cl}^{-}$concentration. But what causes the upregulation of KCC2? A new study by Ganguly et al. provides evidence that it might be GABA itself.

The authors isolated neurons from the rat hippocampus just before birth (embryonic day 18), and cultured the cells over a 13day period. This protocol had previously been shown to accurately replicate the maturation of neurons in vivo over the same time period. They then measured the percentage of neurons in which the intracellular $\mathrm{Ca}^{2+}$ concentration increased in response to GABA. As the cells matured, they became increasingly unresponsive, indicating that the decrease in the excitatory action of GABA could also be found in culture. Blocking the $\mathrm{GABA}_{\mathrm{A}}$ channels with antagonists inhibited this change in responsiveness, and also prevented the switch from GABA-mediated excitation to inhibition. Conversely, the switch was accelerated when $\mathrm{GABA}_{\mathrm{A}}$ receptor activation was increased by treating the cells with $\mathrm{KCl}$ to induce synaptic $\mathrm{GABA}$ release. The authors also observed that GABA regulates the levels of KCC2 mRNA expression, and they suggest a mechanism for this. They propose that depolarizing GABA-mediated potentials activate voltage-dependent calcium channels, setting off a signalling cascade that culminates in the upregulation of KCC2 gene expression. This is further supported by the observation that blocking L-type calcium channels also delayed the switch.

So, Ganguly et al. have provided strong evidence that a causal relationship exists between excitatory GABA-mediated transmission and the levels of KCC2. In this way, GABA could indirectly regulate the $\mathrm{Cl}^{-}$gradient across the cell membrane, leading to a switch in the transmission properties of its own receptor.

Heather Wood

\section{(2) References and links}

ORIGINAL RESEARCH PAPER Ganguly, K. et al. GABA itself promotes the developmenta switch of neuronal GABAergic responses from excitation to inhibition. Cel/ 105, 521-532 (2001)

FURTHER READING Moss, S. J. \& Smart, T. G. Constructing inhibitory synapses. Nature Rev. Neurosci. 2, 240-250 (2001)
H I G H L I G H T S

\section{LEARNING AND MEMORY}

\section{Finding a home for your savings}

You're at the pub and the jukebox suddenly starts playing that song from your teenage years. You haven't heard it for ages and your recollection of the lyrics is sketchy at best. But as you listen, the words quickly come back as if they'd never left you; you can remember the whole song so well again that you cannot get it out of your mind for several days. This uncanny ability to relearn information much faster than on the original training is called 'savings'. Despite its importance, however, our understanding of savings is rudimentary. What is the neural basis of savings? Where is it implemented? In a recent paper, Medina et al. give some tentative answers to these questions in the context of a cerebellum-dependent form of classical conditioning.

Eyelid conditioning is arguably the best-studied form of motor learning. In this model, a rabbit learns to close the eyelid in response to a tone that is repeatedly paired with periorbital electrical stimulation. The neural circuits involved in eyelid conditioning are well understood, and it has been proposed that changes in synaptic strength in the cerebellar cortex and in the deep cerebellar nuclei might be cellular correlates of this form of learning. Armed with this knowledge, Medina et al. built a computer model that could 'learn' and 'extinguish' the eyeblink response, and asked whether it could also show savings during relearning. Indeed, the model relearned faster and they found that residual plasticity in the nucleus interpositus could account for the savings. The authors then predicted that the induction of plasticity in the nucleus interpositus of the actual rabbit should parallel eyelid conditioning, that plasticity should persist after the behavioural response had been extinguished, and that the rate of relearning should correlate

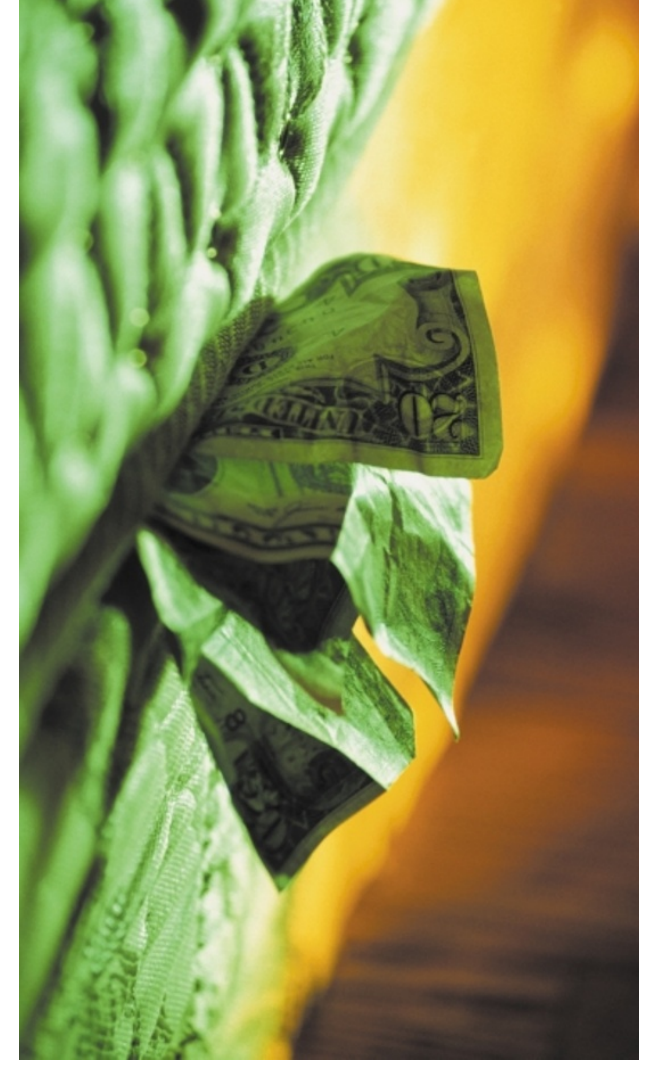

with the amount of residual plasticity in individual rabbits. Indeed, subsequent experiments allowed them to obtain empirical evidence in support of these predictions.

The profound anatomical knowledge of eyelid conditioning was crucial for the success of this study. It would now be interesting to perform similar experiments in other tasks for which the anatomical substrates are well-understood - fear conditioning, for example - to determine whether the mechanism found by Medina et al. is also at work in other systems.

Juan Carlos López

(9) References and links ORIGINAL RESEARCH PAPER Medina, J. F. et al. A mechanism for savings in the cerebellum. J. Neurosci. 21, 4081-4089 (2001) FURTHER READING Medina, J. F. et al. Timing mechanisms in the cerebellum: testing predictions of a large-scale computer simulation. J. Neurosci. 20, 5516-5525 (2000) 